\title{
Gloria de la Fuente y Danae Mlynarz (Eds.). El pueblo unido... Mitos y realidades sobre la participación ciudadana en Chile, Editorial Alberto Hurtado, 2013, 212 pp., Santiago de Chile.
}

\author{
María de los Ángeles Fernández Ramil
}

En la transición a la democracia chilena, algunos temas han devenido en verdaderos convidados de piedra. Nos referimos, en este caso concreto, a la participación ciudadana y a los mecanismos de democracia directa. Desde el punto de vista de lo deseable, pareciera que ha Ilegado la hora de, al menos, conversar en torno a ellos. Asistimos a un Chile en el que las movilizaciones sociales, independientemente de su frecuencia e intensidad, parecen haber llegado para quedarse en el paisaje político y no es aventurado pensar que a su base descansan, entre otros motivos, una demanda por expresividad. Resulta casi una obviedad recordar que se acumulan suficientes indicadores, aunque algunos contradictorios entre sí, que hablan de una mayor conciencia de derechos en la población y de una progresiva intolerancia a la desigualdad y los abusos. Es por ello que los temas que se abordan en El pueblo unido... Mitos y realidades sobre la participación ciudadana en Chile no pueden ser más pertinentes y necesarios. Aunque la motivación inicial del libro nace a partir "del desconocimiento y los déficits observados en la implementación de la ley $20.500^{1}$ aprobada en 2011", su aspiración es mayor: contribuir a establecer el vínculo entre participación y democracia. A partir de los fenómenos de movilización social que, especialmente en 2011, dejaron en evidencia una crisis de representación que viene costando mucho asumir, se declara un doble propósito. Por un lado, "contribuir al debate conceptual respecto de la participación ciudadana" y, por otro, "ofrecer un análisis de la implementación de políticas que van en ese sentido". De forma ordenada y en progresión lógica, logrando reunir a autores que constituyen un referente obligado para este tipo de asuntos, parte ofreciendo un balance de la institucionalidad democrática chilena desde 1990 y las iniciativas legislativas para incluir mecanismos de participación directa, con conclusiones lapidarias ante la falta de voluntad política a la hora de las concreciones. Posteriormente, se incluyen reflexiones que se centran en la gestión local municipal, abordando los mecanismos de participación ciudadana a nivel local y un desarrollo conceptual, para seguir con una propuesta de democracia real a nivel municipal. Posteriormente, se evalúa la implementación y desarrollo de dos mecanismos existentes: la ley de asociación y participación ciudadana, promulgada en 2011, y los plebiscitos comunales. Se incorporan también los análisis de la ley de transparencia y acceso a información pública y del mecanismo de iniciativa popular de ley. Finaliza el libro, de manera pedagógica, con el análisis de caso de implementación de una política pública -la autopista acceso sur- y las consecuencias de no incluir la participación ciudadana temprana. La lectura, más allá de los temas específicos que se abordan, logra su propósito de mostrar los límites e insuficiencias de una democracia representativa que ha terminado por erigirse como el único modelo posible en el marco más amplio de un enfoque de la gobernabilidad

$1 \quad$ Nos referimos a la Ley 20.500 sobre asociaciones y participación ciudadana en la gestión pública, aprobada el 16 de febrero de 2011. 
que, si bien fue funcional para la primera etapa de la transición, hoy muestra síntomas de agotamiento. El procesamiento de las demandas sociales y las fórmulas para expresar las diferencias en el Chile actual se enfrentan a dos vías posibles, constituyendo un menú ciertamente restringido: la elección de representantes a cargos de elección popular o bien lo que la prensa denomina, no sin cierta carga eufemística, "la calle".

Aunque es sabido que las instituciones de la democracia directa son importantes para mejorar la calidad de la democracia, densificándola y entregando vías a los ciudadanos para el derecho a expresión no se observa, en el horizonte actual, señales mínimas de preocupación por incorporarlas con pleno derecho en la estructura del sistema político chileno. En el pasado reciente, cuando ha habido intentos por impulsarlas, no han faltado argumentos de rechazo que van desde que sus impulsores estarían imbuidos por intenciones de reemplazo de la democracia representativa hasta el recurso a experiencias concretas extraídas de otros contextos de la región donde se han implementado con las que Chile (vale decir, sus élites) no desea ser asimilado y que tienen mucho de evidencia selectiva. Dichos argumentos, con falaces, forman parte del discurso público dominante y es posible identificar su cristalización en dos momentos específicos de la historia política reciente. Cuando la ex Presidenta Bachelet, durante el período 2006-2010, hizo suya la consigna de "gobierno ciudadano" como uno de los ejes con los que aspiraba a caracterizar su administración. Para ello, dio a conocer tempranamente una Agenda pro Participación Ciudadana que, finalmente, no tuvo la importancia esperada. En segundo lugar, en plena efervescencia del movimiento estudiantil, en 2011, cuando sus dirigentes movilizados por el tema educacional, junto con rechazar de plano la respuesta del Ministro de Educación de turno con propuestas a sus demandas, plantearon la realización de un plebiscito nacional como solución de las discrepancias. En ese momento se recordó, dentro de los argumentos para atajar dicha pretensión, que la Constitución solamente autoriza ese mecanismo como una atribución presidencial en el caso específico de rechazo en el Congreso, con el voto de los dos tercios de cada cámara, de las observaciones del mandatario a un proyecto de reforma constitucional. Resulta ilustrativo recordar los títulos de algunas columnas de opinión de la época como "La letra chica del plebiscito", "La ilusión plebiscitaria" o "El riesgo populista". El mínimo común denominador de todas ellas era la pretensión de la aparente legitimidad científica de la técnica sobre la política, amparándose en los problemas prácticos y de procedimiento que dicha opción encerraba.

El libro de De la Fuente y Mlynarz invita a preguntarse sinceramente por las razones de nuestra incapacidad para inyectar a la democracia chilena de la dimensión participativa de la que carece. Esta inquietud se profundiza frente a la existencia de cierta unanimidad acerca de la crisis de representación que el país enfrenta. Si bien es cierto que la introducción de mecanismos e instrumentos participativos no alcanzaría, por sí solos, a resolverla, sí resulta inquietante el hecho de que constituya un ámbito prácticamente silenciado cuando se habla de los desafíos que enfrenta la democracia chilena. Por el contrario, se suele observar que el derrotero de los posibles remedios vendría de la mano, por una parte, del intento de cierre de la brecha entre representantes y representados, dentro de los contornos de la democracia representativa y, por otro, de un mayor impulso a la transparencia y de la accountability. Hitos 
recientes que lo ejemplifican se encuentran en la aprobación de la Ley de Acceso a Información Pública y el correspondiente Consejo de Transparencia, la inscripción automática y el voto voluntario y la ley de primarias. El nuevo sistema de inscripción debutó en las elecciones municipales de 2012 y su implementación añadió problemas adicionales de accountability electoral en el proceso de conteo de votos y manejo de los padrones. La ley de primarias para elegir candidatos a cargos de representación a nivel presidencial y parlamentario enfrentará su prueba de fuego durante el año 2013. La máxima concesión que se ha hecho durante la administración Piñera a la dimensión de participación ciudadana ha sido un proyecto de plebiscitos comunales que se encuentra en el Congreso, sin mayor prioridad ni diligencia. El cuadro se completa de forma preocupante cuando se toma nota de los problemas que enfrenta la implementación de la ley de participación ciudadana en la gestión pública a nivel municipal, bien sintetizados en el capítulo de Tomás Marín y Danae Mlynarz.

La evidencia empírica concreta de la aplicación de los mecanismos que el libro aborda, para el caso de América Latina, no justifica los fantasmas que despierta. Daniel Zovatto, en su estudio Las instituciones de la democracia directa a nivel nacional en América Latina: Un balance comparado 1978-2007 concluye que, "pese a la generalizada incorporación de los mecanismos de democracia directa en los textos constitucionales de la región, la mayoría de los sistemas políticos siguen teniendo un bajo componente de democracia directa en el nivel nacional, con excepción del Uruguay y, en menor medida, Ecuador, Panamá y Venezuela". Avanza señalando que "la riqueza sería mayor a nivel estadual y local-municipal, con un resultado mixto y oscilante entre intentos de manipulación neopopulista, por un lado y, con posiciones conservadoras y tradicionalistas, por otra".

Sin embargo, ¿qué hipótesis podrían esgrimirse para explicar su ausencia para el caso chileno? Del libro se desprenden unas cuantas, condensándose especialmente en la reflexión de Gonzalo de la Maza titulada "Participación ciudadana y construcción democrática en Chile: Balance de un cuarto de siglo". Aunque no se desarrollan en profundidad, nos interesa Ilamar la atención sobre los componentes ideológicos que, junto con otros factores como los institucionales, permitirían explicar que "hasta el momento, los actores políticos que se distribuyen el poder institucional -la Concertación y la Alianza- no hayan modificado sus orientaciones consolidadas durante el último cuarto de siglo, que excluyen una modificación de esta naturaleza". En esta segunda línea, resulta de interés no perder de vista la hegemonía de ciertos marcos de sentido interpretativos a nivel del debate público, permeados por una cultura inspirada en la economía neoclásica tal como señala el rector de la UDP, Carlos Peña, en una reciente entrevista. Estos tienen un correlato, a nivel de los actores políticos, pero también de los cultores de la Ciencia Política, más preocupados por identificar el mejor sistema electoral o cuál sería el mecanismo de primarias con menos trade off, en una visión de la democracia de corte capitalista, elitista, conservador y neoliberal.

En este modelo, la representación política es por anticipación, la relación entre representante y representados es de arriba hacia abajo, el grado de independencia de los representantes es total, el control ciudadano es puntual, el valor atribuido a la participación ciudadana es procedimental y el modelo de ciudadanía ya no es liberal, sino libertario, más cercano a la 
idea de ciudadano "consumidor". Corriendo un cierto riesgo, pero no carente de sentido, es posible extrapolar para esta forma de aproximarse y entender la democracia, la afirmación vertida por Pablo Longueira, uno de los máximos dirigentes de la UDI y hoy Ministro, según la cual "si uno mira los gobiernos de la Concertación desde un punto de vista político, estos fueron de centroderecha en sus conceptos e ideas".

Lo concreto es que Chile se caracteriza hoy por una serie de preocupaciones y demandas que no solamente tienen un correlato material en la línea de la redistribución del ingreso. Hay demandas latentes por reconocimiento y representación que difícilmente podrán encontrar un cauce en los marcos estructurales de representación política, tal como hoy se estaría concibiendo como posible. La tarea de la política es la de canalizar el conflicto, manteniéndolo dentro de contornos más o menos controlados y, si se aspira a que esta sea democrática, no puede sino hacerse en el marco de conciliación de intereses diversos en un clima de tolerancia y respeto mutuos, parafraseando a Bernard Crick. Otro autor, Mark Roelofs, invita a la creatividad política y a remover los temores cuando señala que "la gobernabilidad tiene que reinventarse cada veinte años".

Si se insiste en mantener lo existente y eludir estas preocupaciones incluso a nivel del debate que parece propiciar el contexto del año electoral en curso, que no se lamenten entonces aquellos que abominan de las lógicas de la calle y de sus posibles efectos. 